\section{El discurso poético y lingüístico en el cuento "Mr. Wipper" de Pancho Madrigal}

\section{The poetic and linguistic discourse in the story "Mr. Wipper" by Pancho Madrigal}

María Auxiliadora Rosales Solís Universidad Nacional Autónoma de Nicaragua, Managua auxiliadorar2002@gmail.com

Otilia Cortez State University of New York oticortez@gmail.com

(c) UNAN-Managua Recibido: mayo 2016 Aprobado: junio 2016

Ha sido tradición de algunos escritores e intelectuales hispanoamericanos definir las características colectivas del ciudadano representativo de la idiosincrasia de sus pueblos. En Chile, por ejemplo, Isabel Allende en su obra Mi país inventado describe en ciertos pasajes la forma en que percibe a su país y a sus habitantes. De igual manera, Octavio Paz en Laberinto de la Soledad cumple con esa misma misión describiendo a la mujer y al hombre mexicano. Por supuesto en Nicaragua también encontramos a un muy reconocido y querido poeta y periodista, Pablo Antonio Cuadra quien en su libro El nicaragüense pintó al ciudadano común de nuestra tierra pinolera de tal forma, que en él no se escapa esa mirada histórica que ya antes se ha registrado en la obra de teatro El Güegüense, libro en que la gracia, la picardía y la astucia se vuelven sus características esenciales.

Por otro lado, encontramos la tipificación del nicaragüense rural, campesino, pobre y con un nivel de escolarización sino nulo casi ausente, aunque a veces todo solo parece ser una pretensión. Esta descripción se recoge exitosamente en las famosas historias cortas de Pancho Madrigal cuyo autor, Fabio Gadea Mantilla, ha popularizado primeramente a través de la radiodifusión nacional desde hace cincuenta y tres años y que ahora ya esos famosos relatos circulan en pasquines y disco compacto. Quizá se preguntarán, ustedes, ¿cuál es la temática de Pancho Madrigal?

Como cualquier otro pueblo, el de Nicaragua posee leyendas, cuentos y mitos que forman parte de su literatura oral. La mayoría de la gente conserva muchas de estas memorias. Así, es frecuente escuchar relatos de duendes, fantasmas, aparecidos, mujeres que se convierten en monas, brujas, etc. En general, seres maléficos. También esta narrativa permite describir a personajes arquetipos del nicaragüense, tanto sus virtudes como sus defectos.

Todos estos aspectos conforman las redes temáticas utilizadas en los cuentos de Pancho Madrigal, en los que se mezclan elementos míticos, históricos y religiosos con relatos de miedo, guerra, pobreza, ignorancia, amistad; pero todos salpicados de humor y picardía que al final siempre dejan una moraleja.

Otro detalle muy interesante en Pancho Madrigal es que algunos de los elementos que conforman generalmente un cuento se han conservado siguiendo un patrón invariable, tal es el caso de la Mora Limpia (texto musical de entrada a las narraciones), Pancho Madrigal, el narrador; El Galope, el pueblo en donde don Fabio ubicó a Aniceto Prieto, el pícaro, y a otros personajes como Filiberto, doña Genara, la Tula, Carelara, don Pancracio, Felipito y otros. 
Y lo que es más impactante, muchas de las estructuras lingüísticas también se repiten una y otra vez. A pesar de esa invariabilidad, Pancho Madrigal continúa teniendo una gran audiencia en el pueblo nicaragüense. Su aceptación como un personaje típico y representativo de la idiosincrasia popular lo ha llevado a su permanencia cotidiana, a tal punto que en el imaginario colectivo cuando se sorprende a alguien en alguna fechoría (falacia o exageración) se lo compara con Pancho Madrigal: Sos un Pancho Madrigal lo que supone es un mentiroso o un pícaro.

Como en toda historia, existe la posibilidad de analizar en estas narraciones factores como el espacio, el tiempo, los personajes y sus acciones, sin embargo, en nuestro trabajo nos concentraremos en el análisis del discurso lingüístico y poético de un cuento radial denominado Mr. Wipper con el propósito de destacar su valor lingüístico, estético y social. Hasta ahora no se han hecho estudios similares que hagan justicia a la riqueza del lenguaje popular en sus diferentes dimensiones o aspectos.

Nuestro análisis implica hacer referencia al objeto de la lingüística y de la poética. En cuanto a la lingüística hay que recordar que "es la ciencia que engloba a toda la estructura verbal". Dado que "la poética trata de problemas de estructura verbal, entre otros campos, se puede considerar a la misma como parte integrante de la lingüista". Al respecto el mismo Roman Jacobson sostiene que "...muchos rasgos poéticos forman parte de, no sólo de la ciencia del lenguaje, sino también de toda la teoría de los signos, es decir de la semiótica en general".

Además, él plantea que la función poética con las otras funciones de la lengua está presente en el habla de todos los seres humanos desde la infancia y que desempeña un papel crucial en la modelación del discurso. Para este mismo lingüista, la función poética es una de las seis funciones del lenguaje, la cual se distingue de las otras por ser la que comprende la concentración dentro del mensaje verbal en sí mismo (...) Jacobson admite que "La función poética proyecta el principio de equivalencia del eje de la selección sobre el eje de la combinación." Lo que debe de entenderse como esa selección y combinación de las palabras que el hablante hace en su acto enunciativo y de la que resulta la estructura lingüística de la comunicación oral y escrita.

A lo anterior hay que agregar que la función poética no es necesariamente privativa del verso, sino que también puede aparecer como función dominante en cualquier texto escrito en prosa. (Vaugh, 1998)

En el texto verbal y escrito del cuento de Mr. Weper, por ejemplo, se observan en acción todas las funciones del lenguaje en ese ciclo comunicativo entre personajes. Muy obvio, por su nivel de predominio en el texto, es la función emotiva o expresiva enfocada hacia el hablante, que "... aspira a una expresión directa de la actitud de éste hacia lo que está diciendo" (Jacobson). En estos cuentos Aniceto el personaje principal por lo general decora su mensaje con cierta picardía y lo enuncia mayormente con un propósito que conduce al engaño, la burla, la denuncia o la moraleja. En esa enunciación se observa junto a la emoción, varios recursos fonológicos, morfológicos, léxico-semánticos que juegan un papel preponderante en la comunicación no sólo con el interlocutor inmediato, sino también con el oyente exterior al cuento o con el lector del mismo en el caso de la versión escrita.

1 La Mora Limpia es una composición musical instrumental del compositor nicaragüense Justo Santos. Para el imaginario del nicaragüense constituye un segundo himno nacional. Esta se originó en ocasión de las Fiestas Patronales de Santo Domingo de Guzmán. El título de esta melodía alude a los caminos que la procesión de Santo Domingo recorre hasta llegar a Managua. 
Tanto la función emotiva como la poética, conativa, referencial, etc., entran en interacción, de manera que la emoción impuesta en el mensaje como la forma en que se ha sido construido el mismo es producto de ese ciclo inevitable de la comunicación. La belleza resultante de esta interacción lingüística es la que nos interesa resaltar en el cuento "Mr Wipper.

En la producción y enunciación del mensaje de los personajes se evidencia un lenguaje que no es común en todos los campesinos nicaragüenses, aunque sí es cierto que esa forma de expresarse se advierte en algunas zonas del norte del país. No todos los casos fonéticos y fonológicos y de construcción son necesariamente iguales en todos los hablantes de esas zonas. El análisis de los distintos niveles lingüísticos permitirá observar el carácter hiperbólico con que de manera intencionada se habla el español "nicaragüense" en esta narración.

Otro aspecto que se debe tomar en cuenta es el hecho de que el autor Fabio Gadea, ha sido un escritor de programas radiales, empresario, y un político muy reconocido en los últimos tiempos. [2]

Su formación académica y experiencia cultural lo distancian del uso de este sociolecto expresado en el cuento que hace que el autor se ubique fuera de una perspectiva real. Es decir que el señor Gadea reproduce lo que él conoce como habla de algunos campesinos y este acto de reproducción no es más que una imitación y por tanto su discurso no es fidedigno, pero no por eso deja de ser lingüístico y poético. Por otro lado, también hay que considerar que en el proceso de radiodifusión entra en juego otro elemento distanciador de la verdadera forma de hablar del campesino, esta es la participación de un narrador también educado, tal fue el caso de Rodolfo Arana Sándigo y posteriormente la de Don Otto de la Rocha. Como consecuencia el emisor es un reproductor del estereotipo del habla campesina y por lo tanto en la interpretación y reproducción lingüística hay consciencia clara del proceso de selección y continuidad con un propósito ya preconcebido. Otro elemento enriquecedor del proceso comunicativo en este cuento es la presencia del uso del Spanglish a la inversa, hablado por un personaje estadounidense, pero también hablado por Aniceto. La suma de estos factores da como resultado un mosaico lingüístico que dota al texto de esa riqueza poética que hemos venido planteando. Para ubicar al lector u oyente en un texto específico, reseñaremos el cuento de Mr. Wepper para luego analizar los usos lingüísticos a través de los cuales se produce el aspecto estético que encierra lo poético.

Este cuento inicia con la conversación entre Don Pancracio y su esposa Doña Tula acerca de Aniceto, sobrino del primero. Mediante esa conversación el público se da cuenta del gusto por la vagancia que padece ese tan singular sobrino quien en esos momentos no se encuentra en la casa de su tío porque está participando de las celebraciones de la Patria que se hacen el catorce de septiembre por la expulsión de los filibusteros Yankes del país. A su regreso de la fiesta Aniceto se entera de una novedad, Don Pancracio Prieto le comunica del arribo de un yanqui, llamado Mr. Wipper. Además, le informa que el gringo necesita a un asistente o baqueano que lo ayude a explorar el lugar para comprar una finca. La noticia de su tío lo hace sospechar que Mr. Wipper es uno de los tantos filibusteros que han arribado a ciertas zonas del país.

[2] Fue candidato a la presidencia de la republica de Nicaragua en las elecciones del 2011, donde obtuvo el segundo lugar. 
Aniceto, quien, a pesar de no ser muy entusiasta del trabajo, es motivado por su tío y va en búsqueda del gringo a quien se le presenta de una forma muy original y traviesa. En este primer encuentro Aniceto exalta la razón de las celebraciones, fecha en que los nicaragüenses obtuvieron la primera victoria sobre las fuerzas armadas de William Walker, en la llamada Batalla de San Jacinto (1856). La arrogancia de Mr. Wipper lo conduce a negar la derrota y a burlarse según él de la ingenuidad y mentira de Aniceto, diciéndole, Ser puros cuentos porque nunca, ustedes, poder ganar al yanque. Esta reacción hiere los sentimientos patrióticos de Aniceto quien decide aprovechar cualquier situación para probarle al gringo la vulnerabilidad de su gente.

La vivacidad de Aniceto impresiona a Mr. Wipper quien lo contrata y juntos inician la búsqueda de la famosa finca. En ese recorrido Mr. Wipper no puede esconder su carencia de fortaleza ante las incomodidades del viaje. Mientras Aniceto se siente físicamente bien, el gringo se siente cansado y muy sediento por la inclemencia del tiempo. Desesperado por la sed y al no encontrar agua que se la satisficiera, llegan a la casa de un dundo, a quien le compra varios guacales de chicha de piña. Mientras Wipper ingería la bebida, el dundo no paraba de reír, lo que llama la atención primeramente de Aniceto y luego de su acompañante.

Este dundo no para de reir. Yo mejor no tomo chicha 'hay que tomé chicha este yanquee, yo no tomo chicha hueeeeeso... mejor no tomo.

Al notar la risa del tonto, Wipper preguntó ¿De qué reír tanto, este hombre, ¿eh? ¿De qué reír tanto, este hombre?

- Es que anoche le cayeron dos ratones a la olla de la chicha, respondió el dundo. - ¡Beber chicha con ratón ¡Este dundo reírse de mí! Mi darle con este huacal en la cabeza.

- No, con ese huacal no, ese es el huacal donde orina mi mama... ja,ja..."

El burlador del inicio del cuento se vuelve burlado al final. La casualidad le hace justicia a Aniceto quien ríe felizmente, Eso es pa' que aprienda mister. Un nica le ganó a un yanke.

El cuento en general refleja el resentimiento contra el invasor y la necesidad de probar que el nica no es tonto, sino que al contrario posee inteligencia y astucia que puede poner de manifiesto en cualquier situación.

En todo este diálogo se advierte a una serie de manifestaciones lingüísticas y poéticas que embellecen el texto. Pancho Madrigal inicia su narración de la siguiente manera,

-iIdiay!, Wicho ¿qué tal?, hombré. El cuento de hoy, Wichó, hombré, si este cuento es bárbaro, ¿sabés quien lo escribió?, Fabio. ¡Fijate; se llama Mr. Weper, ;óiganlo! [3]

Este saludo dirigido a Wicho, guía al oyente radial quien se entera de que ese cuento va dirigido a una audiencia de la que Wicho forma parte porque a él se lo ubica dentro de la audiencia inmediata, es decir que Wicho es como un narratario en el cuento porque Pancho se lo narra a él como audiencia directa.

A lo anterior se deben sumar las múltiples interjecciones (función fática) que pronuncia Pancho Madrigal al iniciar el cuento. Particularmente, la interjección ¡Hombréi que es un vocativo de uso frecuente en el habla coloquial, sirve para asegurarse de que se mantiene la comunicación, para llamar la atención sobre un dato, para que el interlocutor confirme una opinión del hablante o también llamadas de atención como en:

-Pero, hombré, tiyitó, no ve que estamos en vacaciones.

3 Como fondo musical se escucha una canción muy conocida de Carlos Mejía Godoy La quebradita, música de mazurca propia de la zona norte de Nicaragua 
En este mismo cuento, acerca de Mr. Weper, en la conversación del inicio entre Don Pancracio y doña Tula se denota cierta molestia por parte de Don Pancracio y aburrimiento por parte de su esposa, esto último, manifestado en la respuesta ¿humm? Esta interjección indica la recepción de información, pero que expresa molestia porque sabe que la comunicación no va resultar de su agrado.

Don Pancracio: - Tulaaaá, Doña

Tula: - ¿Huumm?

En las líneas que siguen Don Pancracio expresa su disgusto cuando se entera de que Aniceto no está en la casa y dice:

Don Pancracio: — ¿No ha venido Aniceto?

Doña Gertrudis: —No, no lo he visto.

Don Pancracio: - Con seguridad anda abriendo la jeta... (perdiendo el tiempo) viendo la jura de la bandera.

Doña Gertrudis: — ¡Jesús,i Pancracioó, a todo el mundo le gusta ir a ver los desfiles ¿qué de malo tiene eso?...

Don Pancracio usa la frase "abriendo la jeta" por la expresión estándar, abriendo la boca. Con la sustitución de boca por jeta expresa su enojo ante lo que él considera vagancia por parte de su sobrino Aniceto. La palabra jeta se usa por lo general para referirse al hocico de los animales, así que Don Pancracio afea la boca de Aniceto por su rabia contra él.

En el mismo pasaje se observa el uso de ¡Jesús! una interjección emitida por la anciana para reprochar, de manera muy sutil, su desacuerdo con la afirmación hecha por su esposo sobre el comportamiento de Aniceto. El uso de las exclamaciones en Pancho Madrigal puede oscilar desde el tono amistoso hasta el agresivo, este último es utilizado por Don Pancracio que representa al personaje mandamás y malhumorado.

Otro caso interesante es el que se observa en el diálogo donde Don Pancracio, en tono exhortativo, recrimina a Aniceto para que junte las manos al saludar. Sin embargo, Aniceto sabe que este gesto es propio de los niños como señal de respeto hacia las personas mayores. Ante este llamado de atención, Aniceto se dirige a su tío con un doble sentido, marcado lingüísticamente por la adición del pronombre personal le que añade ambigüedad a la frase, en la que el interlocutor puede entender que se refiere a los órganos sexuales o a su secreción hormonal del día.

Aniceto: - ¡Buenas tardes, mita!, ¡Buenas tardes, tiyito¡Don Pancracio:- Con las manos puestas.

Aniceto- ¿Cómo le amaneció, mi tiyitó...? 


\section{Revista Lengua y Literatura. Vol.2, núm. 1, enero-junio 2016}

En este mismo cuento hay pasajes en que se usan frases con sentido irónico para ridiculizar a Aniceto Prieto que representa al sinvergüenza y haragán.

Don Pancracio: - Me gusta que participés en la semana del descanso. Lo único malo es que vos no solo te tomás la semana del descanso...

Aniceto: - Y ¿qué, pues?

Don Pancracio: - Todo el año.

Adviértase también el uso del pronombre vos que hace Don Pancracio para dirigirse a Aniceto. Su posición de poder le permite vosearlo, dado que él es una persona mayor y además es su tío. Además, la conjugación de los verbos se marca morfológicamente en las formas participés y tomás que no corresponde con la conjugación de la segunda persona singular "tú" que sería participes y tomés.

En Mr. Weper, Aniceto deja de conjugar los verbos y mantiene gran parte de la conversación repitiendo el infinitivo por contagio del problema que tiene Mr.

Weper quien no tiene dominio del idioma.

Aniceto: - Good afternoon, mister ¿usted ser Mr. Weper, ¿verdad? / Mr. Weper: -Yes, oh yes, mi ser Mr Weper- ¿usted, quién ser?

Aniceto: - Mi ser, Anic eto Pray... o sea Praity, una cosa como decir..."

En otros casos, la situación se invierte y mientras el gringo articula y pronuncia bien, Aniceto lo hace a la manera campesina.

Otro aspecto que le añade humor al relato es la fanfarronería de Aniceto al expresar palabras y frases agramaticales en inglés como una forma de igualarse con la posición del yanke.

Aniceto: - ¿What to you said to me and the morning?

En otros enunciados que Aniceto produce en el cuento "Mr. Weper", se observan por ejemplo, ciertas frases dichas por y para el mismo Aniceto, en las que se deja ver su desconfianza hacia Mr. Weper. Con esas mismas frases Aniceto logra un doble juego verbal, expresar sus verdaderos sentimientos para el oyente fuera del ciclo comunicativo y esconderlos de su interlocutor. Con esta estrategia Aniceto superpone un ciclo comunicativo primario a otro externo y paralelo al texto.

Aniceto: — ¿What to you said to me and the morning?

Mr. Weper: -Decir que gustarme como ayudante y pagar veinte pesos al día.

Aniceto: - ¿Dólaresm o pesosm nicas, papá? Decía pues que que que ... [me parece pinche, este viejo, parece filibustero...] Mr. Weper:-¿Qué decir, Aniceto Pray?

Aniceto: - No, no... digo que está bien, está bien [ iqué pinche este carajo!, veinte pesos hummm, iqué árbaroj, iqué árbaroi ] Mr. Weper : — ¿Qué decir, Aniceto Pray?

Aniceto: - No. digo que está bueno, veinte pesos, very good. 


\section{María Rosales Solís Otilia Cortez Pancho Madrigal... pp. 1-9}

En la parte final del cuento hay un caso muy interesante que muestra la satisfacción de Aniceto ante la maldad del dundo contra el gringo. La hora de que el gringo pague la burla que le hizo ha llegado. \{ y Aniceto permite que el dundo Recuérdese que al inicio de la historia el gringo se ha burlado de Aniceto cuando él le dice que andaba en la celebración de las fiestas patrias debido al triunfo de los nicas contra la fuerza gringa representada por William Walker. Ya se ha dicho que Mr. Weper en cierto momento se sintió sediento y que tuvo que comprar chicha para calmarla en la venta de un dundo mal intencionado. )

Cuando Aniceto se percata de la risa maliciosa del dundo, Aniceto no previene de la situación a Mr. Weper y permite que este sea víctima de la maldad del dundo como una forma de probarle al gringo que él no es tan invencible como cree.

Mientras lo deja tomar la chicha contaminada, Aniceto se dice, Esto es pa'que aprienda. ( Mr. Wiper) En el primer caso vemos en la pronunciación de pa' que aprienda la pérdida de la última sílaba "ra" de la palabra para, pero inmediatamente se oye la articulación de la palabra "aprienda" expresada por el supuesto campesino.

En este caso se presenta una sustitución de la palabra aprenda por aprienda, donde se observa la diptongación de tipo: e>ie que por razones sociales y lingüísticas el campesino reproduce de una forma diferente y que en su enunciación los fonemas que ha escuchado no corresponden al uso de la palabra original y sobre esa construcción Gadea Mantilla reproduce en su texto escrito, la variante que su personaje radial repite oralmente. O sea que el proceso va de aprenda a aprienda del campesino, a aprienda reproducido por Gadea y luego por el personaje. Es esta reproducción, en conjunto con todos los demás casos que ya se han señalado, como se logra la forma artística conseguida en el relato.

La expresión "Esto pa'que usted aprienda" contiene una lección moral que tiene el propósito de mostrarle al estadounidense y a la audiencia que el nica no es tonto aunque aparente serlo.

Carlos Mántica[4] comenta que "Fabio [Gadea] es quizás el único "cuentista" que no usa ni abusa de los infinitos giros, dichos y voces del habla nicaragüense, a pesar de que la domina perfectamente". (2007:100). Sin embargo, el análisis realizado al cuento Mr. Wiper nos revela todo lo contrario. 


\section{CONCLUSIONES}

Como se puede notar, la riqueza del cuento no radica en una narrativa especialmente interesante, ni en una trama complicada, sino en el uso del lenguaje y del mensaje a través del cual se caracteriza al nicaragüense popular.

En el cuento sobresale el uso recargado de variantes coloquiales, particularmente el habla nicaragüense del campesino pobre y analfabeta. Esto se refleja reiteradamente en los diálogos característicos de los personajes populares. El autor utiliza un lenguaje con el acento o deje rural, interjecciones y onomatopeyas donde se combina la música folklórica popular y regional con el fin de representar los códigos culturales y las características específicas que hacen el perfil idiosincrásico del nicaragüense.

Esto explica la cantidad de fenómenos dialectales principalmente en el plano sonoro. En los diálogos encontramos: alargamiento o duración del segmento vocálico; desplazamiento del acento, sobre todo en los vocativos,[5] omisión y adición de fonemas, uso abundante de interjecciones coloquiales y hasta prosaicas, entre otros. Asimismo junto con el nivel morfosintáctico y léxico se manifiesta la burla, la ironía y el sarcasmo con que el nicaragüense enfrenta sus carencias y dificultades. 


\section{REFERENCIAS}

Jacobson, Roman. Lingüística y poética. Trad. Ana María Gutiérrez Cabello. Madrid : Cátedra, 1974.

Vaugh, Linda. Roman Jacobson's Science of Language. Netherland: The Peter Ridder Press. 1976. 